\title{
MicroRNA involvement in mammary gland development and breast cancer
}

\author{
Licia Silveri, Gaëlle TiLly, Jean-Luc Vilotte, Fabienne Le ProvosT* \\ Laboratoire de Génétique biochimique et Cytogénétique, Institut National de la Recherche \\ Agronomique, 78350 Jouy-en-Josas, France
}

\begin{abstract}
MicroRNA (miRNA) are small non-coding RNA that post-transcriptionally regulate gene expression. In humans, miRNA genes may account for 2 to $3 \%$ of the total number of genes. Although the biological functions of most miRNA are unknown, their importance for development, cell proliferation, cell death, and morphogenesis has been demonstrated in several species. One could thus speculate that miRNA should be involved in the regulation of one of the organs that can undergo cycles of cell division, differentiation and dedifferentiation in the adult, the mammary gland. In this paper we summarise several reports dealing with the potential implication of miRNA in the mammary gland, most of them focussed on pathological situations, such as the appearance of breast cancer. These data suggest an implication of miRNA on mammary gland biology. However, direct evidence of this is still lacking. Expression profile analysis of miRNA during the normal mammary gland development could help in addressing this question and in identifying miRNA potentially involved. To this aim, we undertook such an analysis on mouse mammary gland at different stages (virgin, pregnancy, lactation and involution) and will present our preliminary results.
\end{abstract}

gene regulation / mouse / RNA interference / mammary tissue

\section{INTRODUCTION}

Over the past few years, our understanding of the regulation of the development of organisms has considerably evolved with the discovery of the pivotal role of small RNA. Firstly identified as potential host defence mechanisms against virus and/or transposons, it was revealed that these small RNA also control expression of endogenous genes in plants and animals at the transcriptional and posttranscriptional levels. The more we learn about them, the more far-reaching appears to be their role. Indeed, it is now estimated that such small RNA may regulate the expression of $20 \%$ of host-encoding genes. Despite intensive research, the num-

\footnotetext{
* Corresponding author:

Fabienne.LeProvost@jouy.inra.fr
}

ber of host-encoded small RNA and their targets remain mostly unknown. Three distinct classes of these small RNA - microRNA (miRNA), small interfering RNA (siRNA), and repeat-associated small interfering RNA (rasiRNA) - are distinguished by their origins, not their functions. In this review, we will focus on the potential role of microRNA in the mammary gland.

\section{MicroRNA: GENERALITIES}

MicroRNA (miRNA) represent a class of naturally occurring small non-coding RNA molecules (19-25 nucleotides in length) whose functions are generally unknown, but believed to be important in development. miRNA originate from genes that are transcribed by RNA polymerase II [1]. miRNA primary 
transcripts (pri-miRNA) are trimmed into miRNA precursors (pre-miRNA) by an RNaseIII-like enzyme called Drosha [2] and subsequently processed by another RNaseIII-like enzyme (Dicer) into miRNA duplexes (miRNA*:miRNA) [3]. One strand of the duplex (miRNA) is then incorporated into the RNA-induced silencing complex (RISC) or miRNAribonucleoprotein particules (miRNP) and the other strand (miRNA*) is degraded. RISC-associated miRNA can target protein-coding messenger RNA (mRNA) either for translation inhibition or degradation (as in RNA interference). Base pairing between the miRNA and its complementary target mRNA gives its specificity to the process (for review, see [4]).

Berezikov et al. [5] estimated that it is possible that as many as 1000 miRNA exist in a vertebrate genome. Based on the previously estimated $250 \mathrm{miRNA}, 10 \%$ of all protein-coding transcripts were thought to be regulated by miRNA [6]. The sequences of many miRNA are conserved between mammals, worms and flies, suggesting an important function mediated through base-pairing. The expression of some miRNA is regulated in a developmental and spatial manner, and the importance of miRNA for development, cell proliferation, cell death, and morphogenesis has been demonstrated in Caenorhabditis elegans, Drosophila melanogaster, and Arabidopsis thaliana [4, 7-9]. In vertebrates, mouse embryonic stem (ES) cellspecific miRNA or miRNA expressed in hematopoietic lineage cells have been cloned $[10,11]$. One of these miRNA (miR-181) was demonstrated to increase Blineage cells when ectopically expressed in hematopoietic stem/progenitor cells, indicating the involvement of this miRNA in differentiation [11]. Recently, expression profiling of a set of rat miRNA in the developing brain and of miRNA associated with polysomes in rat cortical neurons were determined. These results suggest the involvement of some miRNA in brain development $[12,13]$. Overall, despite a yet incomplete knowledge of the function of miRNA, this novel class of regulatory molecules appears to play an important role on the multiplication, differentiation and apoptosis of various cell types. One could thus speculate that miRNA should be involved in the regulation of one of the organs that can undergo cycles of cell division, differentiation and dedifferentiation in the adult, the mammary gland.

\section{MAMMARY GLAND DEVELOPMENT}

The mammary gland is a complex organ constituted by two tissue compartments: the epithelium and the stroma (for review, see [14]). The epithelium consists of ducts and milk-producing alveolar cells. Most epithelial cells are secretory cells, which undergo functional differentiation during pregnancy to produce milk. They are surrounded by myoepithelial cells, which are contractile and allow the delivery of milk. The extensive system of ducts and alveoli is embedded in the stroma, a connective tissue. This tissue is composed mainly of adipocytes, and also contains fibroblasts, neurons, blood vessels and cells of the haematopoietic system. The functional mammary gland is the result of the succession of distinct stages that are defined by the hormonal status of the animal (Fig. 1).

The mammary anlage is established during foetal development. Ductal elongation and branching is achieved principally after puberty. Alveolar proliferation occurs during pregnancy, and functional differentiation is accomplished at parturition and during lactation. At the end of lactation, the loss of suckling stimuli and the pressure build-up on cessation of milk removal initiate involution. This stage causes massive cell death, collapse of the alveoli and remodelling of the epithelial compartment 


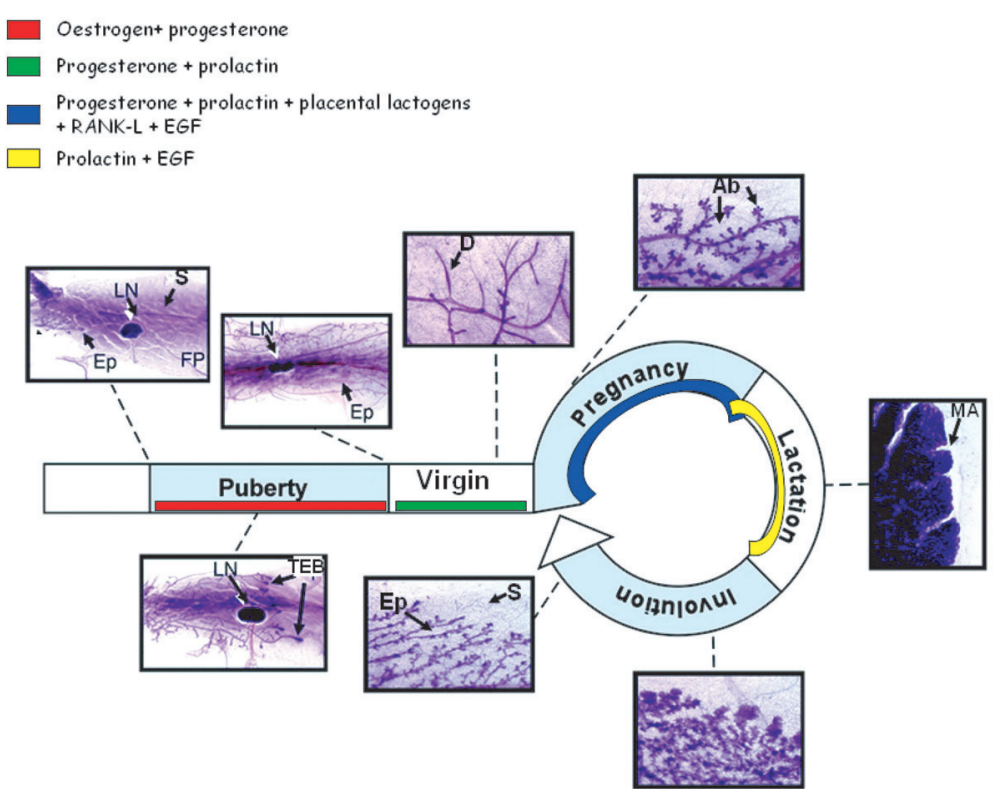

Figure 1. Succession of distinct stages of a functional mouse mammary gland. The different potential developmental stages of the mammary gland during a female lifespan are illustrated. The major hormones that control these processes of proliferation, differentiation and apoptosis are indicated. Ab, alveolar bud; D, duct; Ep, epithelium; FP, fat pad; LN, lymph node; MA, mature alveoli; $\mathrm{S}$, stroma; TEB, terminal end bud. This figure was inspired from the "Biology of the Mammary Gland" WEB page (http://mammary.nih.gov/index.html).

to restore a simple ductal structure. With the next pregnancy, a new round of alveolar expansion, maturation and lactation is initiated.

In the mammary gland, these events are strictly regulated by steroid and peptide hormones. During puberty, the cyclical production of ovarian oestrogen and progesterone accelerates ductal outgrowth and branching. During pregnancy, prolactin and placental lactogens control the proliferation and maturation of the alveolar compartment. Apoptosis is under an endocrine regulation with a decline of the systemic concentration of prolactin and growth hormone [15].

The tight and complex regulation of mammary development has been exten- sively studied over the years at the genetic, physiological and morphological levels. Surprisingly, yet only a few reports have assessed the potential implication of miRNA in normal mammary development, most of them focussing on pathological situations, such as the appearance of breast cancer, and so for obvious human health related purposes.

\section{MicroRNA AND MAMMARY GLAND BIOLOGY: CURRENT REPORTS}

\subsection{Human breast tissue has a specific miRNA expression profile}

Liu et al. [16] recently described a methodology for human and mouse 
miRNA gene expression profiling based on microchip technology. This microchip microarray contains 368 genespecific oligonucleotides generated from 248 miRNA (161 derived from human-, 84 from mouse- and 3 from Arabidopsis thaliana-miRNA). A panel of 20 RNA samples isolated from 18 adult and 2 foetal normal human tissues was analysed. It revealed that each tissue has a specific pattern of miRNome expression (defined as the full complement of miRNA in a cell) that can be quantified. For example some miRNA are only highly expressed in one or few tissues, such as miR-1b-2 or $m i R-99 b$ in the brain or the closely related $m i R-133 a$ and $m i R-133 b$ in skeletal muscle, heart, and prostate. The human "breast"-specific signature is characterised by the expression profile of 23 miRNA. In this study, the breast is the tissue with the lower number of detected miRNA. In the 21 other tissues analysed, between 34 and 187 miRNA were detected.

Although this report highlights that a specific set of miRNA are present in the mammary tissue, several questions remain unanswered: the physiological status of the studied breast sample was not given and the potential evolution of the miRNA expression profile during mammary development was not analysed. It thus only suggests that miRNA could be involved in the mammary gland physiology. Another indirect evidence of such an implication came from the analysis of breast tumours.

\section{2. miRNA are differentially expressed in normal and tumour breast cells}

Studies from the last three years have demonstrated that expression of miRNA genes is altered in several human malignancies, including chronic lymphocytic leukaemia, pediatric Burkitt lymphoma, gastric and lung cancers, and large cell lymphoma, suggesting that they may play a role as a novel class of oncogenes or of tumour suppressor genes $([17,18]$, for review, see [19-21]). It was shown that mutations in genes required for miRNA biosynthesis can induce developmental defects and cancer further stressing the importance of miRNA in cancer (for review, see [20, 22]). In 2002, Calin et al. [23] showed that miR-15a and miR-16a, located at $13 \mathrm{q} 14$, are frequently deleted and/or down-regulated in patients with $\mathrm{B}$ cell chronic lymphocytic leukaemia. In a more global study, it was reported that $52.5 \%$ of the 186 studied miRNA genes are located in cancer-associated genomic regions or in fragile sites [24]. Among those, 15 miRNA are located in 10 breakpoint regions involved in human breast cancers [24].

Expression of 222 pre-miRNA was studied by real-time PCR in 32 commonly used cell lines, including 5 breast cancer ones (T47D, SKBR3, MDA361, MCF7 and MDA231) [25]. This study revealed that let-7f-1 is increased by 7 -fold in the epithelial-derived breast, lung and colorectal cancer cells. However no pre-miRNA specific from breast cancer cell lines could be detected. It should be emphasised that these data involved pre-miRNA and not the active, mature miRNA. The relationship between the expression of the pre- and the mature miRNA has not yet been thoroughly addressed. The miRNA microarray was used to evaluate miRNA expression profiles in 10 normal and 76 neoplastic breast tissues [26]. Twenty-nine miRNA were found to be differentially regulated of which a set of 15 that could be used to predict with $100 \%$ accuracy the nature of the cell sample analysed (i.e., tumour or normal breast tissue). Expression of some miRNA could be correlated with specific breast cancer biopathologic features, such as estrogen and progesterone receptor expression, tumour stage, vascular invasion, or proliferation index. High expression of human miR-125b seems to be present in differentiated cells or tissues [27]. It was observed that breast cancer primary 
Table I. Expression level of 22 miRNA in the mouse mammary gland. Expression level of miRNA was assessed by northern blot analysis of mammary gland total RNA (20 $\mu \mathrm{g})$. A methionine tRNA probe has been used to normalise RNA loadings. - Undetected, + low expression level, +++ high expression level.

\begin{tabular}{lc}
\hline miRNA & Expression level \\
\hline let-7a, let-7b, let-7c, mir-26a, mir-26b & +++ \\
mir-24-2, mir-145, mir-30b, mir-30d & + \\
mir-140, mir-217, mir-203, mir-23b, mir-7.1, & \\
mir-30c-1, mir-212, mir-100, mir-92.1, & - \\
mir-216, mir-142, mir-130a, miR-125b & \\
\hline
\end{tabular}

tumours have a decreased expression level of $m i R-125 b$ compared to normal breast tissue, suggesting that down-regulation of miR-125b impairs the differentiation capability of cancer cells.

Again, these data suggest an implication of miRNA in mammary gland biology. However, direct evidence of this is still lacking. Expression profile analysis of miRNA during normal mammary gland development could help in addressing this question and in identifying the miRNA potentially involved. To this aim, we undertook such an analysis on mouse mammary gland focussing on twenty-two miRNA, ten of them were chosen because they have potential targets within mouse mammary EST and the remaining because they were reported to be expressed in human breast tissue. Although still preliminary, our current data highlighted potential interesting features.

\section{3. miRNA during normal mammary gland development, differentiation and involution}

\subsubsection{Detected miRNA are present at all developmental stages}

Occurrence of the miRNA was assessed by northern blot analysis of total mammary RNA from virgin, early-, mid- and lategestating, lactating and early involuting mice. Only nine of the twenty-two analysed miRNA could be detected (Tab. I). The thirteen remaining were either absent from the mammary tissue or expressed at levels below the detection limit of northern blot analysis. More sensitive approaches have recently been described for analysing miRNA expression based on RT-PCR [28]. Such experiments could be performed to confirm one or the other hypothesis.

Surprisingly, $m i R-125 b$ was among the undetected miRNA. Indeed two recent studies have described this miRNA as being highly expressed in differentiated cells or tissues [26, 27]. It was shown by northern blot analysis that human breast cancer primary tumours have a decreased expression level of $m i R-125 b$ as compared to normal breast tissue, suggesting that lack of miR-125b may impair differentiation capabilities of cancer cells [26]. Our results were not in accordance with these studies. Whether this discrepancy is related to differences in the sensitivity of the experiments or to species specificity remains to be assessed.

We also compared our results with those of the pre-miRNA profiles found in human breast cancer cell lines [25] (Tab. II). Some miRNA seemed to be detected only in the normal mammary gland, whereas others were only detected in cancer samples. However the detection techniques used and the detected RNA (pre- versus 
Table II. Comparison of 22 miRNA expression levels between normal mouse mammary gland and human breast cancer cell lines. In the mouse mammary gland, the expression levels of 22 miRNA have been studied by northern blot analysis and classified as 2 types (detected or undetected). The corresponding pre-miRNA expressions, described in several human breast cancer cell lines by real-time PCR method [25], were classified as 2 types (high or low expressed).

\begin{tabular}{lccc}
\hline & & $\begin{array}{c}\text { Human breast cancer } \\
\text { cell lines }\end{array}$ \\
\hline & $\begin{array}{c}\text { Expression } \\
\text { level }\end{array}$ & High & Low \\
\hline $\begin{array}{l}\text { Normal } \\
\text { mouse } \\
\text { mammary } \\
\text { gland }\end{array}$ & Detected & 6 & 3 \\
\hline
\end{tabular}

The data for the human breast cancer cell lines are derived from Jiang et al. [24]

mature miRNA) were different, making the evaluation of the significance of this observation difficult. It remains that it would be of interest to check if the expression of some miRNA could be used as molecular markers of the normal or cancerous status of mammary tissues.

Surprisingly, all the nine miRNA that we detected were present at each developmental stage studied. This could suggest that these miRNA have no direct implication on the development and/or differentiation of the mammary gland. Indeed, one would expect such miRNA to be only present at specific stages to control time and spatial expression of sets of mRNA. However, quantitative analysis of the expression pattern of some of these miRNA will be necessary to know if a more complex regulation pathway occurs. It should also be emphasised that the mammary gland is a complex organ composed of various cell types. Thus, the overall miRNA expression patterns observed might hide cell-type specific miRNA regulation.

\subsubsection{Future directions}

\subsubsection{1. miRNA expression in mammary epithelial cells}

As a first approach to assess if some miRNA are developmentally regulated in mammary epithelial cells, we undertook northern blot analysis of miRNA on total RNA samples extracted from $\mathrm{HC} 11$ cells at different differentiation stages. HC11 cells are mouse mammary epithelial cells derived from mid-pregnant mice that can be induced to differentiate at confluence by hormonal treatment. This analysis should allow us to follow miRNA expression profiles within epithelial cells that are differently stimulated. Alternatively, it was recently described that locked nucleic acid (LNA)-modified DNA probes could be used to follow the miRNA expression profile in mouse embryos by in situ hybridisation [29]. Such a strategy could reveal the precise location of miRNA within the mammary tissue at various developmental stages.

\subsubsection{Cloning of mammary miRNA}

Lactation is a late emerging function during evolution. miRNA implication in the control of such a physiological process could involve the regulation by evolutionary-conserved miRNA of new genes. Alternatively, it could result from the emergence of cell- and stage-specific miRNA [30]. Indeed, it was recently shown that the world of miRNA is not limited to conserved sequences and that a substantial portion of miRNA are primate-specific [31]. Although introducing potential bias, cDNA cloning is a possible approach to identify such miRNA. By doing so, we cloned potential miRNA. They include some, such as let-7c, that we could already detect by northern blot analysis, indirectly validating our strategy. Some sequences obtained did not match any known 
miRNA. We are currently analysing if these cDNAs fulfil the criteria that will allow them to be classified as newly identified miRNA [30].

\subsubsection{Search for mammary miRNA target pairs}

Studies on miRNA will be complete only when their role and their target(s) will be determined. At present only a few pairs of the miRNA:target have been characterised [30]. Some genes are known to be key actors of mammary development. Implication of miRNA in the regulation of some of these genes have been described in non-mammary cells. It is tempting to assess if a similar mechanism is reproduced in the mammary gland. The involvement of members of the Bcl-2 family in the control of mammary epithelial apoptosis [32] and of breast cancers [33] has been described. It was also recently demonstrated that $m i R-15 a$ and $m i R-16-1$ expression is inversely correlated to that of $\mathrm{Bcl}-2$ in chronic lymphocytic leukaemia and that both miRNA negatively regulate $\mathrm{Bcl}-2$ at a posttranscriptional level [34]. Bcl-2 repression by these miRNA induces apoptosis in a leukemic cell model. Therefore, $m i R-15 a$ and $m i R-16-1$ are natural antisens Bcl-2 inter-actors. It would be interesting to know if these two miRNA are involved in normal mammary gland transformation. We are currently performing experiments to answer this point.

\section{ACKNOWLEDGEMENTS}

L. Silveri is supported by the Rivage program (European Community Marie Curie Actions). We thank Nathalie Chesnais and José Costa for providing the mice.

\section{REFERENCES}

[1] Lee Y, Kim M, Han J, Yeom KH, Lee S, Baek SH, Kim VN. MicroRNA genes are transcribed by RNA polymerase II. Embo J 2004, 23: 4051-4060.

[2] Lee Y, Ahn C, Han J, Choi H, Kim J, Yim J, Lee J, Provost P, Radmark O, Kim S, Kim VN. The nuclear RNase III Drosha initiates microRNA processing. Nature 2003, 425: 415-419.

[3] Hutvagner G, Mclachlan J, Pasquinelli A.E, Balint E, Tuschl T, Zamore PD. A cellular function for the RNA-interference enzyme Dicer in the maturation of the let-7 small temporal RNA. Science 2001, 293: 834-838.

[4] Bartel DP. MicroRNAs: genomics, biogenesis, mechanism, and function. Cell 2004, 116: 281-297.

[5] Berezikov E, Guryev V, Van De Belt J, Wienholds E, Plasterk RH, Cuppen E. Phylogenetic shadowing and computational identification of human microRNA genes. Cell 2005, 120: 21-24.

[6] John B, Enright A.J, Aravin A, Tuschl T, Sander C, Marks DS. Human MicroRNA targets. PLoS Biol 2004, 2: e363.

[7] Ambros V. MicroRNA pathways in flies and worms: growth, death, fat, stress, and timing. Cell 2003, 113: 673-676.

[8] Carrington JC, Ambros V. Role of microRNAs in plant and animal development. Science 2003, 301: 336-338.

[9] Boehm M, Slack F. A developmental timing microRNA and its target regulate life span in C. elegans. Science 2005, 310: 1954-1957.

[10] Houbaviy HB, Murray MF, Sharp PA. Embryonic stem cell-specific microRNAs. Dev Cell 2003, 5: 351-358.

[11] Chen CZ, Li L, Lodish HF, Bartel DP. MicroRNAs modulate hematopoietic lineage differentiation. Science 2004, 303: 83-86.

[12] Krichevsky AM, King KS, Donahue CP, Khrapko K, Kosik KS. A microRNA array reveals extensive regulation of microRNAs during brain development. RNA 2003, 9: 1274-1281.

[13] Kim J, Krichevsky A, Grad Y, Hayes GD, Kosik KS, Church GM, Ruvkun G. Identification of many microRNAs that copurify with polyribosomes in mammalian neurons. Proc Natl Acad Sci USA 2004, 101: 360-365.

[14] Hennighausen L, Robinson G.W. Information networks in the mammary gland. Nat Rev Mol Cell Biol 2005, 6: 715-725.

[15] Travers MT, Barber MC, Tonner E, Quarrie L, Wilde CJ, Flint DJ. The role of prolactin 
and growth hormone in the regulation of casein gene expression and mammary cell survival: relationships to milk synthesis and secretion. Endocrinology 1996, 137: 15301539.

[16] Liu CG, Calin GA, Meloon B, Gamliel N, Sevignani C, Ferracin M, Dumitru CD, Shimizu M, Zupo S, Dono M, Alder H, Bullrich F, Negrini M, Croce C M. An oligonucleotide microchip for genome-wide microRNA profiling in human and mouse tissues. Proc Natl Acad Sci USA 2004, 101: 9740-9744.

[17] He L, Thomson JM, Hemann MT, HernandoMonge E, Mu D, Goodson S, Powers S, Cordon-Cardo C, Lowe SW, Hannon GJ, Hammond SM. A microRNA polycistron as a potential human oncogene. Nature 2005, 435: 828-833.

[18] Lu J, Getz G, Miska EA, Alvarez-Saavedra E, Lamb J, Peck D, Sweet-Cordero A, Ebert B , Mak RH, Ferrando AA, Downing JR, Jacks T, Horvitz HR, Golub TR. MicroRNA expression profiles classify human cancers. Nature 2005, 435: 834-838.

[19] McManus MT. MicroRNAs and cancer. Semin Cancer Biol 2003, 13: 253-258.

[20] Gregory RI, Shiekhattar R. MicroRNA biogenesis and cancer. Cancer Res 2005, 65: 3509-3512.

[21] Esquela-Kerscher A, Slack FJ. OncomirsmicroRNAs with a role in cancer. Nat Rev Cancer 2006, 6: 259-269.

[22] Carmell MA, Xuan Z, Zhang MQ, Hannon GJ. The Argonaute family: tentacles that reach into RNAi, developmental control, stem cell maintenance, and tumorigenesis. Genes Dev 2002, 16: 2733-2742.

[23] Calin GA, Dumitru CD, Shimizu M, Bichi R, Zupo S, Noch E, Aldler H, Rattan S, Keating M, Rai K, Rassenti L, Kipps T, Negrini M, Bullrich F, Croce CM. Frequent deletions and down-regulation of micro- RNA genes miR15 and miR16 at 13q14 in chronic lymphocytic leukemia. Proc Natl Acad Sci USA 2002, 99: 15524-15529.

[24] Calin GA, Sevignani C, Dumitru CD, Hyslop T, Noch E, Yendamuri S, Shimizu M, Rattan S, Bullrich F, Negrini M, Croce CM. Human microRNA genes are frequently located at fragile sites and genomic regions involved in cancers. Proc Natl Acad Sci USA 2004, 101: 2999-3004.

[25] Jiang J, Lee EJ, Gusev Y, Schmittgen TD. Real-time expression profiling of mi-
croRNA precursors in human cancer cell lines. Nucleic Acids Res 2005, 33: 5394 5403.

[26] Iorio MV, Ferracin M, Liu CG, Veronese A, Spizzo R, Sabbioni S, Magri E, Pedriali M, Fabbri M, Campiglio M, Menard S, Palazzo JP, Rosenberg A, Musiani P, Volinia S, Nenci I, Calin GA, Querzoli P, Negrini M, Croce CM. MicroRNA gene expression deregulation in human breast cancer. Cancer Res 2005, 65: 7065-7070.

[27] Lee YS, Kim HK, Chung S, Kim KS, Dutta A. Depletion of human micro-RNA miR$125 \mathrm{~b}$ reveals that it is critical for the proliferation of differentiated cells but not for the down-regulation of putative targets during differentiation. J Biol Chem 2005, 280: 16635-16641.

[28] Chen C, Ridzon DA, Broomer AJ, Zhou Z, Lee DH, Nguyen JT, Barbisin M, Xu NL, Mahuvakar VR, Andersen MR, Lao KQ, Livak KJ, Guegler KJ. Real-time quantification of microRNAs by stem-loop RT-PCR. Nucleic Acids Res 2005, 33: e179.

[29] Kloosterman WP, Wienholds E, De Bruijn E, Kauppinen S, Plasterk RH. In situ detection of miRNAs in animal embryos using LNA-modified oligonucleotide probes. Nat Methods 2006, 3: 27-29.

[30] Wienholds E, Plasterk RH. MicroRNA function in animal development. FEBS Lett 2005, 579: 5911-5922.

[31] Bentwich I, Avniel A, Karov Y, Aharonov R, Gilad S, Barad O, Barzilai A, Einat P, Einav U, Meiri E, Sharon E, Spector Y, Bentwich Z. Identification of hundreds of conserved and nonconserved human microRNAs. Nat Genet 2005, 37: 766-770.

[32] Metcalfe AD, Hickman JA, Streuli CH. Programmed cell death and the mammary gland-the involvement of the Bcl-2 family members in the control of epithelial apoptosis. Biochem Soc Trans 1996, 24: 347S.

[33] Schorr K, Li M, Krajewski S, Reed JC, Furth P. A Bcl-2 gene family and related proteins in mammary gland involution and breast cancer. J Mammary Gland Biol Neoplasia 1999, 4: $153-164$

[34] Cimmino A, Calin GA, Fabbri M, Iorio M V, Ferracin M, Shimizu M, Wojcik SE, Aqeilan RI, Zupo S, Dono M, Rassenti L, Alder H, Volinia S, Liu CG, Kipps TJ, Negrini $\mathrm{M}$, Croce CM. miR-15 and miR-16 induce apoptosis by targeting BCL2. Proc Natl Acad Sci USA 2005, 102: 13944-13949. 